NASA Technical Memorandum 107010

\title{
$p-11$
}

\section{Robust Rocket Engine Concept}

Carl F. Lorenzo

Lewis Research Center

Cleveland, Ohio

Prepared for the

31st Joint Propulsion Conference and Exhibit cosponsored by AIAA, ASME, SAE, and ASEE

San Diego, California, July 10-12, 1995
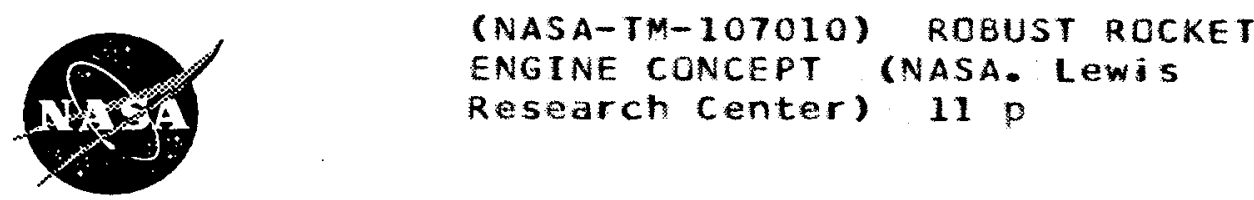
17 


\title{
ROBUST ROCKET ENGINE CONCEPT
}

\author{
CARL F. LORENZO \\ NASA LEWIS RESEARCH CENTER \\ 21000 BROOKPARK ROAD, CLEVELAND, OHIO 44135 \\ MAIL STOP 77-1 \\ (216)-433-3733
}

\begin{abstract}
The potential for a revolutionary step in the durability of Reusable Rocket Engines is made possible by the combination of several emerging technologies. The recent creation and analytical demonstration of Life Extending (or Damage Mitigating) Control technology enables rapid rocket engine transients with minimum fatigue and creep damage. This technology has been further enhanced by the formulation of very simple but conservative Continuum Damage models. These new ideas when combined with recent advances in Multidisciplinary Optimization provide the potential for a large (revolutionary) step in reusable rocket engine durability. This concept has been named the Robust Rocket Engine Concept (RREC) and is the basic contribution of this paper. The concept also includes consideration of design innovations to minimize critical point damage.
\end{abstract}

\section{Introduction}

Durability remains a paramount issue in the area of reusable rocket engines. The world's only reusable rocket engine, the Space Shuttle Main Engine (SSME), has exhibited a variety of durability issues as summarized in reference 1. A number of issues have been corrected by redesign of some of the components, however, significant life improvement remains possible in some areas for example, the turbine blades and thrust chamber. Recent advances in the area of Life Extending (Damage Mitigating) control, continuum damage modelling, and multidisciplinary optimization allow the vision of a revolutionary step in reusable rocket engine durability. This vision has been called the Robust Rocket Engine Concept (RREC). The fundamental idea is to simultaneously optimize both the design and operation of the rocket engine to minimize damage while maintaining good dynamic response and with minimum impact on performance. This is done at critical times in the mission and for critical points in the engine structure.

The robust rocket engine concept also considers the addition of hardware to allow damage minimization to be effected. This might include such things as the capability to preheat turbine engine blades to minimize start-up thermal transient effects.

\section{Multidisciplinary Aspects}

The development of the robust rocket engine concept will require an advanced form of multidisciplinary engineering. It must bring together simultaneously: aspects of cycle design, pumping and turbine issues, combustion initiation, engine control issues, as well as advanced multidisciplinary optimization techniques. For the RREC concept to be successful it will require a variety of disciplines to work together effectively and at the detail level. This includes aerodynamics. structures,materials science, combustion science and controls. The following discussion attempts to highlight some of the areas and issues.

\section{Critical Damage Points/Operating Domains} Important aspects of the robust rocket engine concept are the location of the critical damage points in the rocket engine structure and identification of the critical operating domains. Based on the Space Shuttle Main Engine (SSME) experience the critical damage points will be those points of high temperature, pressure, speed, and rates of change of temperature with time. Typically this will include areas like the turbine blades, particularly the turbine blade roots, possibly, the pump impellers and areas of extreme high temperature and heat flux such as the main chamber jacket and nozzle liners. 
The periods of extreme operating conditions have been clearly identified in the SSME to be the start-up transient prior to going into controlled operation and the shut-down condition. Obviously the overall design of the engine must include the effects of steady state operation, although this would not likely have a dominant impact on the overall fatigue damage accumulation.

\section{Cycle Design}

Traditionally the choice of cycle for rocket engines has been based on performance, cost, and weight with typically after-the-fact attention to such issues as durability. Clearly the choice of the cycle is important relative to the issue of engine durability. The effect of the cycle on durability, particularly during start-up and shut-down transients is critical.

The cycle-optimization needs to be done at two levels. The first level is the gross choice of the cycle topology, ie. the component selection and the plumbing connections. Literally hundreds of cycle topologies, variations, and advanced concepts are possible (Ref. 2). Various cycle studies often yield a generalization of both the benefits and limitations of the major cycles. It may be possible to design specific cycles or to alter existing cycles to improve durability of critical components with little loss in performance. With current technology the gross selection of the cycle topology will probably be done in a nonautomated manner.

After the topology is chosen the second level of optimization is the refinement of the flows,pressures, and bypass requirements and the way in which the cycle is balanced and optimized for both steady and transient performance and durability. This is done for the operating conditions expected for the engine. It is important that the high damage operating conditions also be considered, in particular the start-up and shutdown modes of operation. This second level of optimization is best done as a part of the overall multidisciplinary optimization (discussed later). A discussion of several different types of rocket engine cycles and a traditional design study are presented in (ref. 3).

\section{Combustion Initiation}

The constraints on the establishment of combustion in the main chamber and if necessary in pre-burner chambers may require better definition than in the past. It is important to know. in defining the constraint space of the optimization process, how broadly one may choose various combustion delays, and hence the rates of change of propellant flows since these indirectly determine the critical stresses and hence damage accumulations. Currently the rocket engine start-up process is somewhat of an art form, with propellant delays and ignition delays empirically based. This approach was satisfactory in the era of expendable engines. However, optimization of the start-up (and shut-down) process will likely require more a more detailed understanding of the combustion initiation process.

Additional research may be needed to describe the domains of safe light-off conditions, acceptable rates of change of power, flow rates, etc for the chosen propellant combinations for use in the optimization studies.

\section{Pumping/Turbine Issues}

The requirements for pumping initiation critically affect the condition of the turbo-pumps at start-up conditions. The chill-down requirements which establish cryogenic initial temperatures in the turbopump are followed by a flow of high temperature gas over the turbine blades. This creates extreme rates of temperature change in the turbine blades and induces large stresses which add to those caused by flow forces and rotation. This is one of the primary causes of turbine blade damage. Methods must be developed to reduce the rate of change of temperature with respect to time of the turbine blades. This is contrary to the manner in which we have approached engine chill-down in the past which has been to cold soak long enough to assure cryogenic flow in the pumps to avoid the possibility of cavitation. It is now necessary to try to minimize the chill-down time not only to minimize propellant usage but to attempt to keep the turbine blades at as high a temperature as possible to minimize thermal stresses. Previously investigated mechanisms such as pump coatings (Ref 4 ) may be useful in this regard.

Design innovations which will minimize thermal conduction between the pumps and the turbines will also be useful. In addition to this, the consideration of adding mechanisms to allow pre-heating of the turbine blades prior to introduction of hot gases to the turbines would also allow for a reduction of thermal shock to the turbine blades.

Part of the optimization process for the robust rocket 
engine concept would likely include aero structural optimization. That is, use of multidisciplinary optimization to design more robust turbine blades and turbine blade shapes to optimize blade life with minimum impact on performance. This process should be somewhat analogous to the multidisciplinary design of wing airfoils/structure for aircraft,which has been demonstrated (Ref 5).

\section{Operation for Minimum Damage}

Important to the design of the Robust Rocket Engine Concept is the manner in which the engine is operated particularly through transients. Recent research results (references 6 and 7) have indicated the ability to tailor the manner by which an engine is controlled through transients to allow damage to be reduced in a profound way. The ratio of accumulated damage for unoptimized transients versus optimized transients have been shown to be as high as three to one or greater. The technique used to accomplish these results is called Life Extending (or Damage

Mitigating) Control. Key results ( Ref. 7) for a reusable hydrogen oxygen bi-propellant rocket engine (schematic Figure 1) going through controlled transients determine the propellant valve positions (flows) verses time to minimize turbine blade root fatigue damage for various sets of constraints (Figure 2 ). The constraints are on damage rate and include the cases of unconstrained damage rate, and damage rate constrained to $5^{*} 10^{-6}$ and $2 * 10^{-6}$. Similar benefits are achieved when the creep damage of the rocket chamber cooling jacket are also incorporated into the optimization(Ref. 8).

It can be seen from the above results that the accumulated damage of both the hydrogen and oxygen turbines is a strong function of the manner in which the engine is carried through the transients. It is also apparent that the dynamic response of chamber pressure and mixture ratio are nearly unaffected by the constraint chosen. This is due to the extreme non-linearity of damage with stress (Ref. 9). The technology developed for Life Extending Control thus becomes a powerful tool which can be applied to the RREC concept.

The achievement of such results is greatly enhanced through the availability of a continuum damage model as opposed to cyclic based damage models. A continuum damage model also enables the optimization process in a practical sense. Recently very concise continuum damage laws have been derived based on the local strain, cyclic damage model (ref. 9). These results also give very simple damage expressions for both the zero mean stress condition as well as the condition of positive or negative mean stress. Figure 3 ) shows the damage rate as a function of a stress level (for a critical component) with mean stress $\left(\sigma_{m}\right)$ as a parameter. Also shown on the figure is a maximum damage rate $\delta(\sigma)_{\max }$ where

$$
\delta_{\max }^{\prime}(\sigma)=\frac{2(1+b)^{-(1+b) / b}}{\sigma_{f}^{\prime}-\sigma}
$$

Here $b$ and $\sigma_{f}{ }^{\prime}$ are material properties and $\sigma$ is the critical location stress. This concise equation form will be particularly useful for optimization studies. In as much current technology is to start rocket engines in an open loop manner it is proposed that at least initially the Life Extending Control technology be used to determine open loop valve schedules that would be applied during the start-up. Later the benefits of closed loop control during start-up may be determined.

\section{Engine Control Issues}

While it is not necessary to control(in a closed loop sense) the rocket engine during start-up or shut-down transients, it may be desirable during steady-state operation to add sensors and/or actuators to reduce the up-side excursions of critical temperatures. Likely locations of these, for example, may be in pre-burners and at the turbine blades. This capability has been demonstrated (ref. 7). In addition, while full closed loop control is not necessary during start-up or shutdown, it may be desirable to accommodate hysteresis and/or slow response in large valves by the introduction of vernier valves and appropriate sensing and logic. Damage can also be reduced during normal operation (i.e. not in start-up or shut-down) through the use of Life Extending Control (Ref. 6 and 7) during controlled transients.

\section{Optimization and Computation Issues}

Important to the robust rocket engine concept is the simultaneous optimization of the operation and the 
design of the engine. With the availability of the Life Extending Control theory and the development of compact continuum damage models the emerging art in multidisciplinary optimization can be used as a fundamental tool to the development of the Robust Rocket Engine. Important progress has been made in recent years in the area of multidisciplinary optimization by various researchers (Refs. 11-13). The achievements include: aircraft aft tail design for minimum drag, aircraft flutter suppression, dynamic decoupling of oblique wing aircraft (Ref. 11) and aero/structural design of lifting surfaces (Ref. 5 ).

The application of multidisciplinary optimization to the design of the RREC can be viewed as a combined design and trajectory optimization problem where the valve schedule during start-up and shut-down is the trajectory. The performance criteria for this problem will consider: traditional performance, weight,damage and life cycle cost. Some of these may of course be combined.

The flow chart Fig(4) shows one possible way to approach this optimization. Substantial parts of the flow chart can be automated using computer optimization and design codes, however, not all parts of the process should be automated. In particular the function of choice of gross cycle topology may be difficult to automate initially.

The process breaks down into the key steps shown in the figure. The initial steps are; choice of a gross topology,. selection of specific sizes, flows, and design point conditions of that topology, and aero/ structural optimization of turbine blades, pump blades, chamber design, and other critical components of the engine. Once the hardware design is temporarily fixed the operation may be optimized. This will determine key transient conditions such as thermal rates causing stress conditions in the turbine blades. The process as shown and discussed here is serial. However, it is important to simultaneously optimize both the design and operation of the engine.

Following convergence of the internal optimization loop the performance over a single flight would is calculated. The calculation would include a system weight, propellant weight increment caused by the start-up transient and/or shut-down transient, thrust response time and life or durability. This is followed by a decision point to see if the performance measure is continuing to improve in which case the geometry may be continued to be varied until it stabilizes. If the geometry stabilizes on a constraint, the question would then be, can the constraint be relaxed by the choice of the cycle or the implementation of the cycle.

Clearly the overall process is computationally intense and would probably require advanced parallel processing to implement. In addition a fast, concise, and reasonably accurate start-up and shut-down simulation of the rocket engine (including structure) will be required as well as very simple damage forms that can be used in the optimization. How much of the process should be computerized is a matter of finding the right balance between computer based formal optimization and conventional design iteration. It will be the challenge for the initial applications of this approach. Clearly, minimal damage of the critical components over the entire flight with high performance is the optimization goal.

\section{New Hardware}

As mentioned in several of the previous sections, it may be desirable to introduce new hardware into the rocket engine. These would include a. a turbine preheat capability. b. vernier valves for accurate control over flows to allow more accurate control of mean turbine blade stresses and c. possibly new materials for the thrust chambers to minimize creep damage and $d$. isolation methods in the turbo pumps to minimize heat conduction and chill down of the turbine blades. Finally, the addition of sensors/actuators to the control system during steady state operations should help minimize thermal excursions of the turbine blades and increase durability.

\section{Summary}

This paper has presented a concept for a potentially revolutionary step in rocket engine durability. The concept is based strongly on recent advances which minimize damage accumulation through transients using the methods of life extending control and the availability of concise continuum damage models together with advanced forms of multidisciplinary optimization. The cost of progress along these lines is the transition to a highly interdisciplinary or multidisciplinary approach, heavy use of computers for design and optimization, and the availability of 
fast engine start models, which includes the effects of fill-time as well as other transient effects. It is believed that durability improvements of greater than ten times may be achieved by such an approach with little loss in steady and dynamic performance.

\section{REFERENCES}

1.)Cikanek, H. A. (1987) "Characteristics of Space Shuttle Main Engine Failures," in 23rd AIAA/SAE/ ASME Joint Propulsion Conference, Paper No. 871939, San Diego,Ca., 29 June -2 July 1987

2.)Kramer, R. and Martin, J."Undeveloped Rocket Cycle Applications to Advanced Earth to Orbit Transportation" in 26th AIAA/SAE/ASEE Joint Propulsion Conference, Paper No. 90-2438, 16-18 July 1990 / Orlando, FL

3.)Stout, D. J., et al (1972) "Orbit-to-Orbit Shuttle Engine Design Study," Final Report, AFRPL-TR-7227 , July 1972

4.)Wong, G. S. (1973) "Liquid Hydrogen Turbopump Rapid Start Program," NAS8-27608, Oct 1978

5.)Wakayama, S. and Kroo, I. "A Method for Lifting Surface Design Using Nonlinear Optimization" in AIAA/AHS/ASEE Aircraft Design, Systems and Operations Conference, 17-19 Sept. 1990 Dayton, $\mathrm{OH}$ AIAA Paper No. 90-3290

6.)Lorenzo, C. F. and Merrill, W. C. (1991) "Life Extending Control: A Concept Paper," in Proc. of American Control Conference, Boston, Mass. 26-28 June 1991
7.)Ray, A.,Wu, M.K, Dai,X., Carpino, M., and Lorenzo,C.F. 1993 Damage-Mitigating of Space Propulsion Systems for High Performance and Extended Life Paper No.AIAA 93-2080, in 29th AIAA/SAE/ASME/ASEE Joint Propulsion Conference, Monterey, Ca., 28-30 June 1993

8.)Ray, A. and Dai, X. "Damage-Mitigating Control of a Reusable Rocket Engine for High Performance and Extended Life" NASA Contractor Report 4640, January 1995

9.)Lorenzo, C. F. (1994) "Continuum Fatigue Damage Modeling for Use in Life Extending Control" NASA TM 106691, LeRC, Cleveland, OH., Aug 1994

10.)Lorenzo, C. F. and Musgrave, J.L . (1992) "Overview of Rocket Engine Control" NASA TM 105318, LeRC, Cleveland OH., Jan, 1992

11.)Morris, S. J. and Kroo, I. "Aircraft Design Optimization with Dynamic Performance Constraints" Journal of Aircraft Vol. 27, No. 12 Dec. 1990

12.)Kroo,1. M. "An Interactive System for Aircraft Design and Optimization" Paper No. AIAA 92-1190 in 1992 Aerospace Design Conference Feb. 3-6, 1992 Irvine, $\mathrm{CA}$

13.)Cramer, E.J.,Dennis,J.E.Jr., Frank,P.D.,Lewis, R.M. and Shubin,G.R. "Problem Formulation for Multidisciplinary Optimization" SIAM Journal of Optimization Vol. 4, No. 4 p.754-776, Nov. 1994 


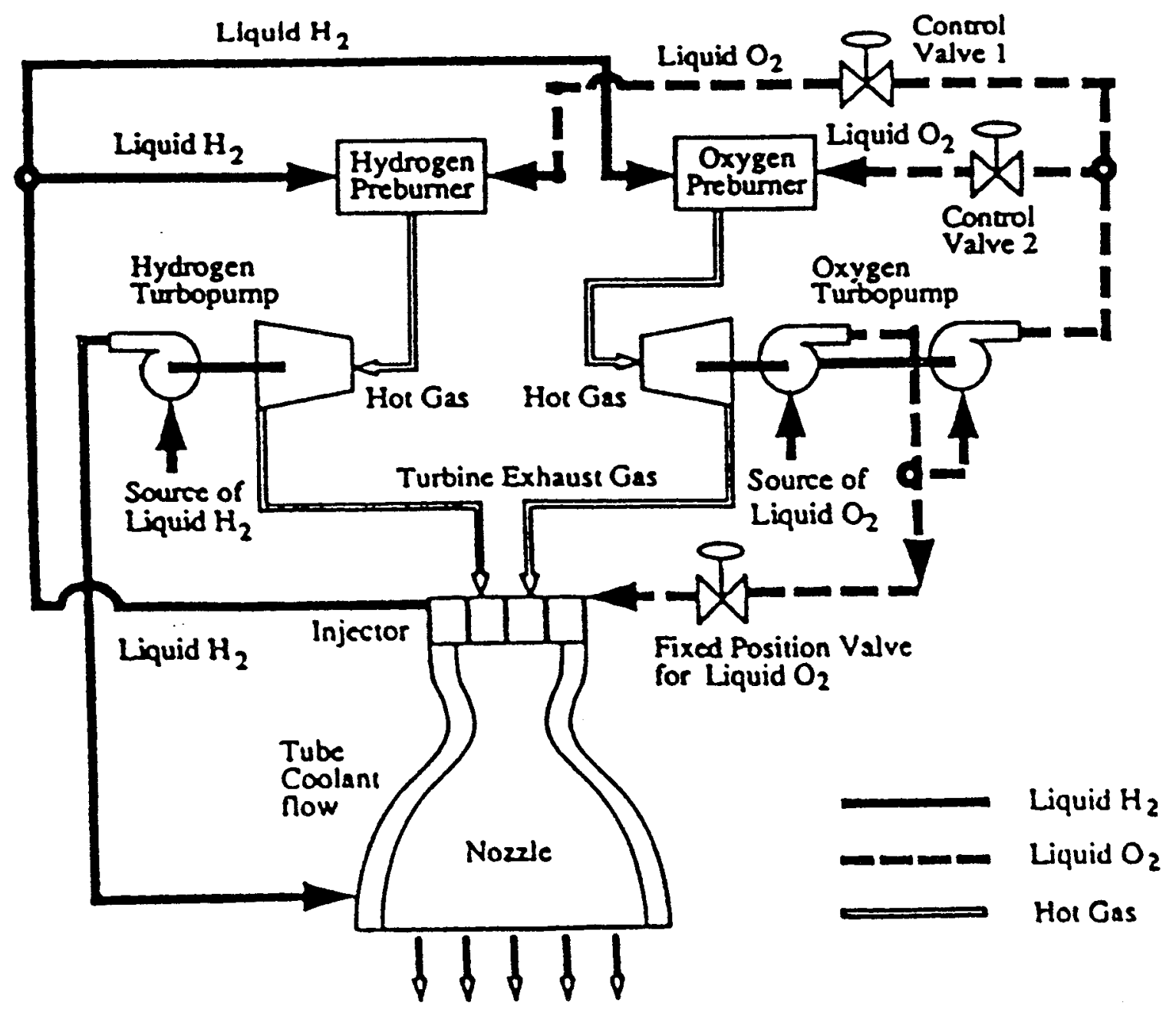

Figure 1. Schematic diagram of bipropellant rocket engine 

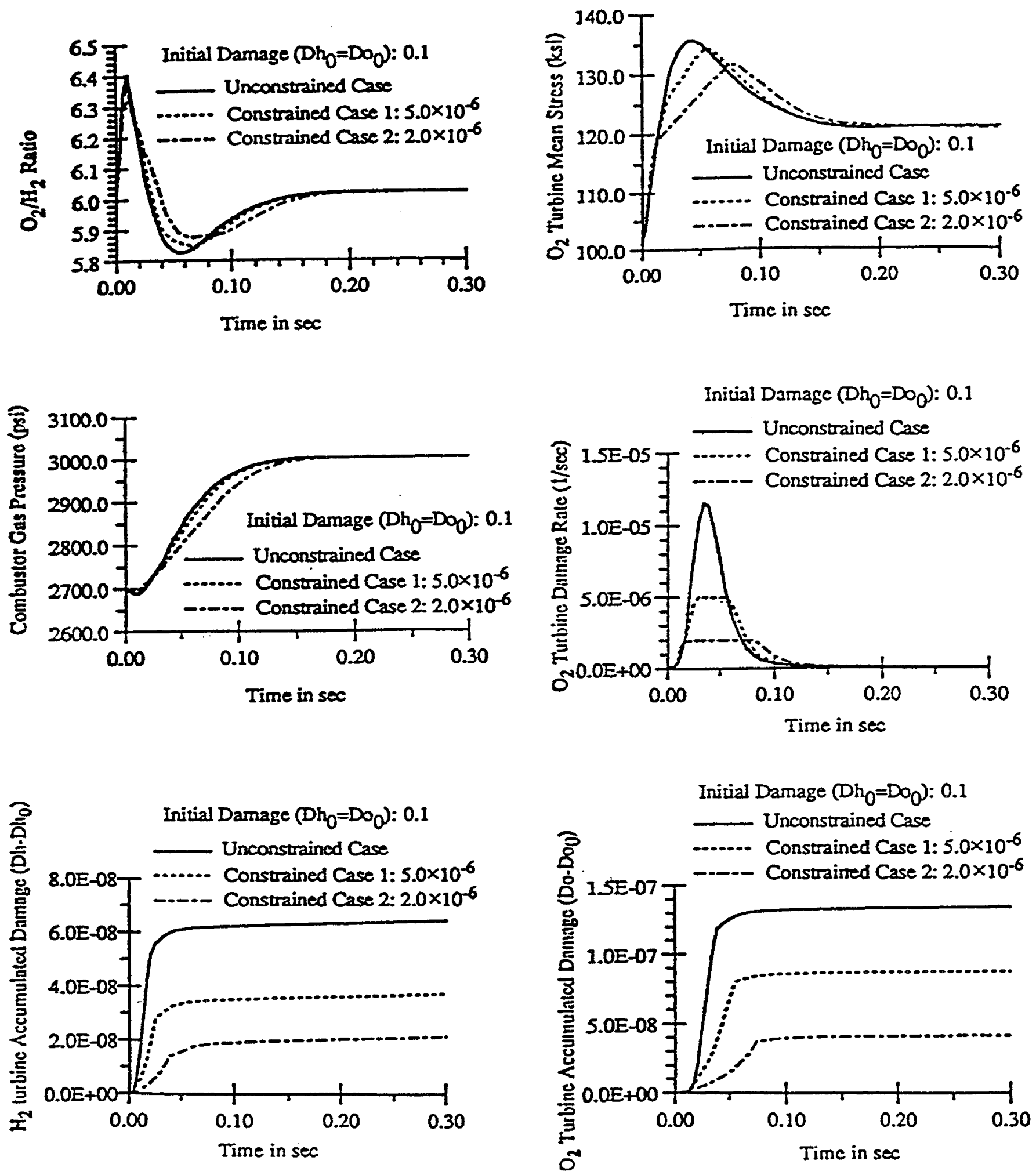

Figure 2. Rocket engine transient responses 


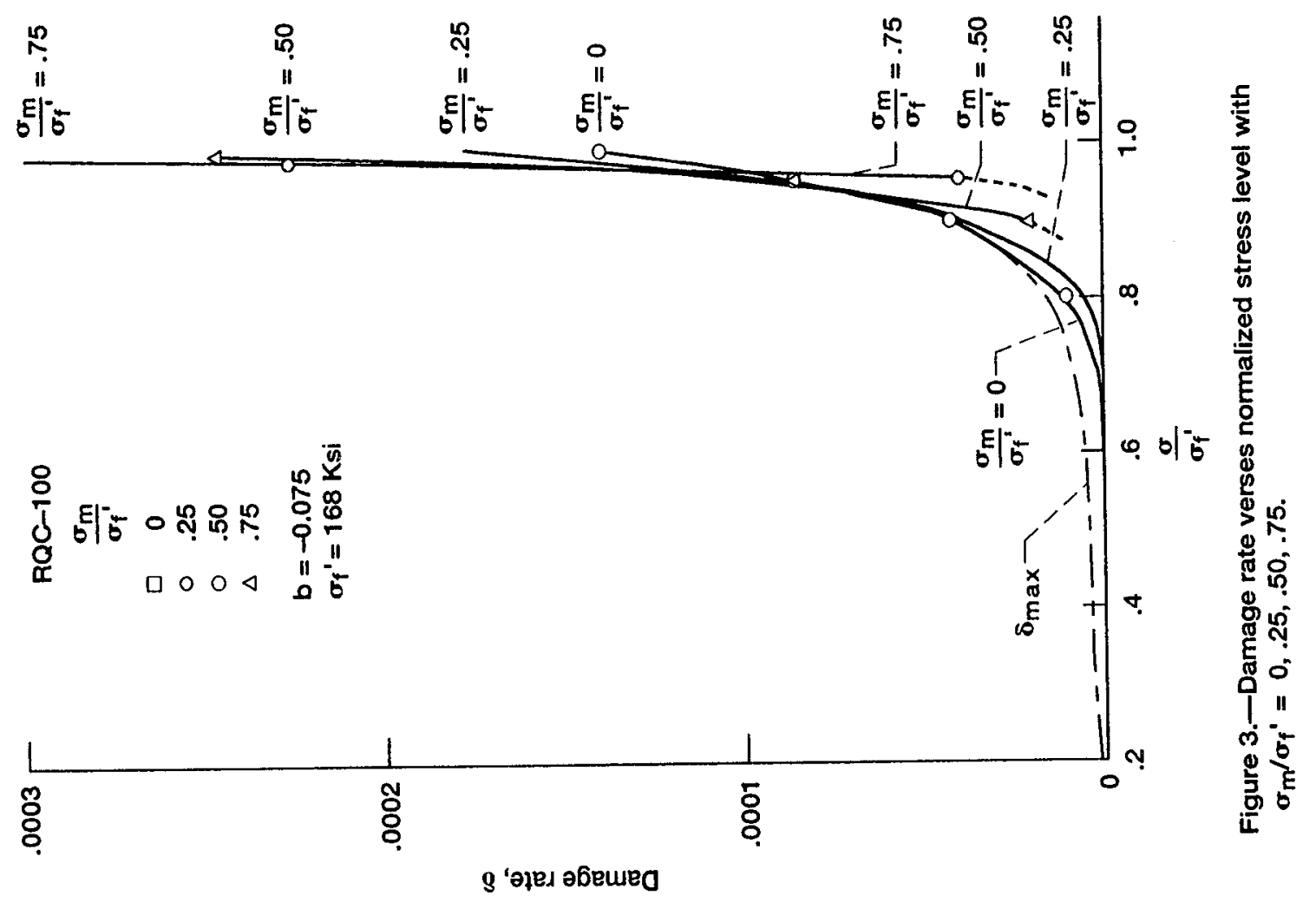




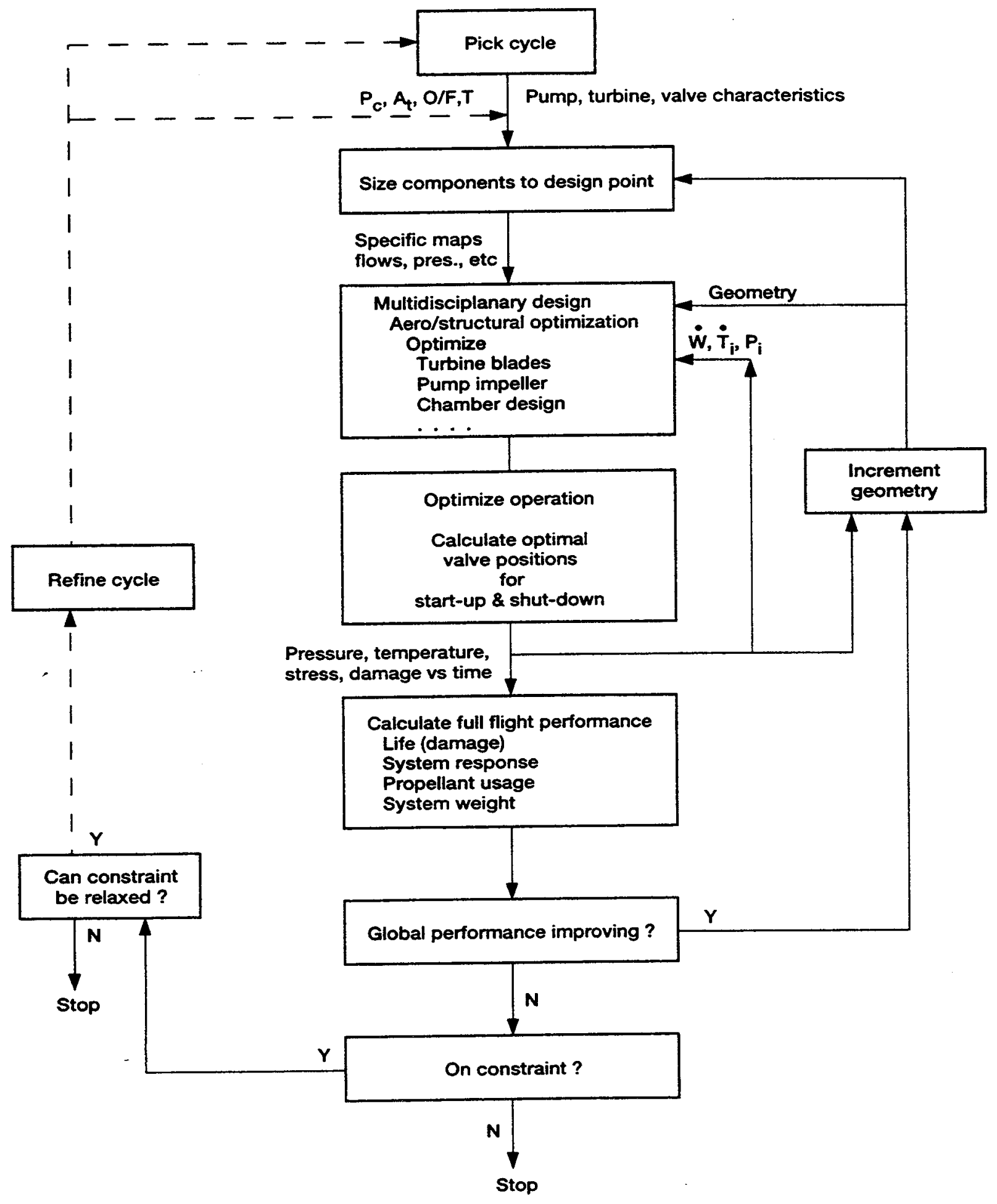

Figure 4.-Multidisciplinary optimization process for robust rocket engine concept. 


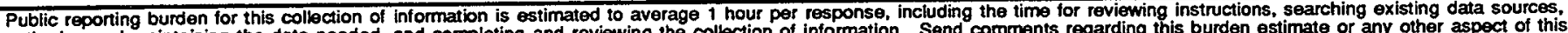
gathering and maintaining the data needed, and completing and reviewing the collection of information. Send comments regarding this burden estimate or any other aspect of this coloctorito

Davis Highway, Suite 1204, Arlington, VA 22202-4302, and to the Office of Management and Budget, Paperwork Reduction Project (0704-0188), Washing
\begin{tabular}{l|l|l|} 
1. AGENCY USE ONLY (Leave blank) & 2. REPORT DATE & 3. REPOFT TYPE AND DATES COVERED
\end{tabular}
July 1995
Technical Memorandum

4. TITLE AND SUBTITLE 5. FUNDING NUMBERS

Robust Rocket Engine Concept

6. AUTHOR(S)

WU-505-62-50

Carl F. Lorenzo

7. PERFORMING ORGANIZATION NAME(S) AND ADDRESS(ES)

8. PERFORMING ORGANIZATION REPORT NUMBER

National Aeronautics and Space Administration

Lewis Research Center

E-9794

Cleveland, Ohio 44135-3191

9. SPONSORING/MONITORING AGENCY NAME(S) AND ADDRESS(ES)

10. SPONSORING/MONITORING AGENCY REPORT NUMBER

National Aeronautics and Space Administration

Washington, D.C. 20546-0001

NASA TM-107010

11. SUPPLEMENTARY NOTES

Prepared for the 31st Joint Propulsion Conference and Exhibit, cosponsored by AIAA, ASME, SAE, and ASEE, San

Diego, California, July 10-12, 1995. Responsible person, Carl F. Lorenzo, organization code 2500, (216) 433-3733.

\section{2a. DISTRIBUTIONAVAILABILITY STATEMENT}

12b. DISTRIBUTION CODE

Unclassified - Unlimited

Subject Category 20

This publication is available from the NASA Center for Aerospace Information, (301) 621-0390.

13. ABSTRACT (Maximum 200 words)

The potential for a revolutionary step in the durability of Reusable Rocket Engines is made possible by the combination of several emerging technologies. The recent creation and analytical demonstration of Life Extending (or Damage Mitigating) Control technology enables rapid rocket engine transients with minimum fatigue and creep damage. This technology has been further enhanced by the formulation of very simple but conservative Continuum Damage models. These new ideas when combined with recent advances in Multidisciplinary Optimization provide the potential for a large (revolutionary) step in reusable rocket engine durability. This concept has been named the Robust Rocket Engine Concept (RREC) and is the basic contribution of this paper. The concept also includes consideration of design innovations to minimize critical point damage.

14. SUBJECT TERMS

Rocket engine; Durabiliy; Multidisciplinary; Design; Life extending control; Damage mitigating control; Continuum damage model; Optimization; Robust

\begin{tabular}{l} 
15. NUMBER OF PAGES \\
11 \\
\hline $\begin{array}{c}\text { 16. PRICE CODE } \\
\text { AO3 }\end{array}$
\end{tabular}

17. SECURTY CLASSIFICATION
OF REPORT
Unclassified

NSN 7540-01-280-5500

\section{SECURITY CLASSIFICATION OF THIS PAGE Unclassified}

\section{SECURITY CLASSIFICATION OF ABSTRACT Unclassified}

20. LIMITATION OF ABSTRACT

Standard Form 298 (Rev. 2-89) Prescribed by ANSI Sid. Z39-18 298-102 